\title{
Impact of digitalization on the evolution of internal corporate institutions in the northern resource-extraction region
}

\author{
Vadim Faruarovich Islamutdinov * \\ Yugra State University, st. Chekhov, 16, 628011 Khanty-Mansiysk, Russian Federation
}

\begin{abstract}
The article examines domestic and foreign sources that study the impact of digitalization on the evolution of intracorporate institutions. Then the state of internal corporate institutions in the northern resourceextracting region - KhMAO-Yugra is considered. The author's features of the classification of intracorporate institutions are proposed. Institutional traps of intracorporate institutions are identified and described, both allRussian: the trap of the authoritarianism of the head and the trap of information asymmetry, and specific to Yugra KhMAD: the trap of bureaucracy, the trap of incentive payments and the trap of low unemployment. The influence of digitalization on the evolution of internal corporate institutions in the northern resource-extraction region is shown, including on overcoming old institutional traps and on the emergence of the new ones: the trap of ease of interaction and the trap of trust in the algorithms. The impact of the coronavirus pandemic on the pace of digitalization of internal corporate institutions in -Yugra KhMAD, which lags behind the global ones, was especially noted.
\end{abstract}

\section{Introduction}

The development of digital technologies has an increasing impact on all aspects of economic activity, including the evolution of intracorporate (intrafirm) institutions. On the one hand, these processes are proceeding within the framework of the general trend towards digitalization, on the other hand, intracorporate institutions are a more hidden field of study from the view of scientists, and a number of processes are almost asymptomatic. The evolution of internal corporate institutions accelerated especially strongly during the coronavirus pandemic and the massive transfer of employees to a remote format. This, in turn, revealed the contradictions and opportunities hidden up to this point in labor collectives, when it turned out that a significant part of the work can be quite acceptable to be performed remotely or replaced by information systems, and some of the employees, having gone to the "remote work", are no longer ready to return to the office for offline work.

In addition, the specificity of the northern resource-extraction region leads to additional features of the evolution of internal corporate institutions under the influence of

\footnotetext{
*Corresponding author: isvad74@gmail.com
} 
digitalization. In particular, the remote nature of work in the context of the coronavirus pandemic forced many employees of large and small companies in Yugra KhMAD to think about the objective need to physically be in difficult natural and climatic conditions. Also, "remote" experience has increased the self-esteem of many employees and now allows them to apply for positions in large federal and international companies. At the same time, the companies themselves have greatly revised their needs for employees and their requirements for them, especially in terms of physical presence on the territory of Yugra As a result, we are already seeing a decrease in the number of vacancies and an increase in unemployment in Yugra.

In article [1], we analyzed the qualitative change in the institutional environment under the influence of the spread of new digital technologies, such as artificial intelligence, digital platforms, blockchain, and the Internet of Things. The positive effects, as well as the threats and risks of digitalization of the economy, have been identified. It was revealed that digital technologies significantly reduce transaction costs and thereby destroy existing institutional traps. Extrapolation of this trend into the future has shown that the "death of institutions" does not threaten us, but at the same time the effect of the Coase theorem should be fully manifested. However, existing institutions are under pressure from digital technologies, transforming or dying. At the same time, there are areas of an institutional vacuum, when new digital technologies remain insufficiently institutionalized for quite a long time, and their capabilities are not fully used. It is shown that the influence of digital technologies on the institutional environment can be direct and indirect. At the same time, the essence of the qualitative changes taking place in the institutional environment under the influence of digitalization can be summarized in the following options: digitalization (algorithmization) of the institutions themselves, increasing the efficiency of existing institutions, destruction of existing institutional traps and the emergence of new ones, the emergence of an institutional vacuum, destruction and decrease in the effectiveness of existing institutions (structures, agreements).

As an example of domestic complex work on the study of the impact of digitalization on internal corporate institutions, you can take the dissertation of Yu.I. Gribanov. [2], where he examined the formation of key competencies of personnel in the process of digital transformation and digitalization of the economy, and also studied the business model based on the digital platform and its role in digital transformation, and based on this substantiated the project mechanism for the digital transformation of enterprises with the participation of a service integrator.

Another Russian author [3] examined how digital economy technologies are changing the living conditions and economic behavior of people, focusing on business behavior and new opportunities in the business environment. He also analyzed organizational forms and new methods of doing business in the context of digital transformation and digital economy.

In his article [4], Parshin A.V. considered the possibility of developing elements of the institutional system of a firm in the context of accumulating corporate knowledge of an explicit and implicit form. He especially drew attention to the problems of implementing the in-house training institute, as well as options for overcoming contradictions in the formation of information and cognitive spaces of enterprises.

T.V. Kramin considered intra-firm institutions as an element of company value management. At the same time, he notes, "that innovations in the information sphere give companies the opportunity to reduce transaction costs of agency relations, as well as increase the transparency of relations with partners and investors. Consequently, the role of in-house institutions is growing even more "[5, p. 2].

Among the foreign studies, it is worth noting the article [6], in which the authors studied how digital communication tools are used for internal communication in transnational 
corporations (TNCs). In particular, the study illustrates the role of digital channels in internal communication, the benefits they bring, and the difficulties associated with using them. Based on this, the authors conclude that digital tools can facilitate internal communications in TNCs, although some problems may arise in connection with the planning of their use.

Another group of foreign researchers in their article [7] notes that the increase in digitalization has influenced various activities, including the business models of companies, allowing the creation of various new forms of cooperation between the companies and leading to the emergence of new products and services, as well as new forms of relationships of the companies with the customers and the employees. To assess the impact of digitalization, they collected quality empirical data from 12 key respondents across two different industries: media and automotive. Research has been conducted to examine the differences and similarities between how digitalization affects value creation, supply, and company takeover, and how firms cope with the challenges posed by increasing digitalization.

Urbach N. and Röglinger M. in the chapter of the monograph [8] talked about best practices and lessons learned from organizations that have succeeded in solving problems and seizing the opportunities of the digital economy. They showed how 21 organizations used their capabilities to create disruptive innovations, develop digital business models, and digitally transform themselves. These cases relate to different industries and countries and cover many aspects that digitalization can have, including in terms of the evolution of internal corporate institutions.

The authors of this work [9] analyzed the impact of technology development on organizational behavior. The most important digital technologies were identified and an analysis of their impact on employees and management was carried out.

The purpose of the study [10] was to identify and demonstrate the key factors in the development of strategic business management in light of the recent waves of digital transformation faced by companies around the world. The above study showed that digital transformation is a worldwide phenomenon; however, regional impact varies significantly depending on the regulatory framework and the level of economic complexity. In fact, the disruptive nature of this trend can undermine the foundations of industries, requiring firms to fundamentally change their approach to strategic management.

A review of the references showed that despite a fairly wide range of studies on the impact of informatization on intracorporate institutions, the issues of the formation and destruction of institutional traps, as well as the specifics of intracorporate institutions in the northern resource-extraction region, have not been sufficiently studied, which determines the relevance of this study.

\section{Materials and methods}

\subsection{The state of internal corporate institutions in Yugra KhMAD}

Intracorporate institutions are inherently a kind of relational routines, since they regulate the relationship between the employees of the firm and their main function is to reduce the transaction costs of interaction within the corporation by coordinating actions, smoothing out conflicts, engaging in joint projects, etc. Internal corporate institutions can be classified according to the following criteria:

1. By the degree of formalization: formal and informal

2. By functions performed: coordinating, stimulating, smoothing out the conflicts 
3. By the degree of digitalization: offline and online.

Formal internal corporate institutions include:

- internal rules of conduct;

- regulations on compensation;

- provision on incentive payments;

- regulations on corporate culture;

Informal intracorporate institutions function on the basis of interest groups, which can technically be formalized in the form of groups in social networks and various messengers. Informal intra-firm institutions include as follows:

- informal leadership;

- rules for the organization of corporate events;

- the rules of the "behind-the-scenes" struggle for the resources and the attention of the leader.

The analysis of intracorporate institutions in Yugra KhMAD showed that, with rare exceptions, they are very poorly formalized. Many local companies do not have local corporate culture regulations. Basically, issues of internal corporate culture and rules are monitored only in those organizations that are subdivisions of larger companies: vertically integrated oil companies, federal networks, etc. Also, certain rudiments of intracorporate culture can be observed in regional institutions, but there they are mainly limited to the adoption of local regulations, and no one really monitors the compliance with the rules and regulations prescribed therein.

\subsection{Description of institutional traps of intracorporate institutions of Yugra KhMAD}

Internal corporate institutions in Yugra KhMAD are subject to approximately the same traps as in Russia as a whole, although there are certain specificities associated with the socio-economic specifics of the region.

All-Russian institutional traps of internal corporate institutions:

\section{The leader's authoritarian trap}

The essence of this trap lies in the fact that the tendency towards paternalism and passivity inherent in Russian employees leads to the fact that the manager has to constantly turn on the administrative resource in order to achieve any results from his subordinates, and for this he has to arrange periodic "hassles" for them. As a result, subordinates get used to the fact that initiative is punishable, that the leader will do it his way anyway, which means that there is no point in taking the initiative, but you just need to get the solution out of the leader and execute it.

\section{Information asymmetry trap}

This trap follows from the previous one and is manifested in the fact that the tougher the leader behaves towards his subordinates, the less information about their activities the subordinates try to disclose to the leader. As a result, the manager receives less and less feedback, loses understanding of the state of affairs and begins to face sudden blockages and rush jobs. And attempts to establish a network of informers lead to the fact that they become information brokers and filter information in their own interests, using it in the behind-the-scenes struggle.

Specific institutional traps that are typical for firms in Yugra KhMAD to a greater extent than for other regions are:

\section{The bureaucracy trap}

Bureaucratization is inherent in all large corporations, however, subsidiaries of vertically integrated oil companies (VICs), headquartered in Moscow or St. Petersburg, are very common in Yugra KhMAD. As a result, the solution of many rather small and 
operational issues is delayed due to the need for agreement "at the top". Moreover, this practice has spread to other sectors of the economy as federal structures take over local companies. In particular, this has already happened in the banking sector, in the pharmaceutical industry, in telecommunications, in retail, etc.

\section{$2 . \quad$ Incentive payouts trap}

This trap is very specific, and it is connected with the fact that the labor resources of Yugra KhMAD were formed and continue to form from among the most mobile and active residents of other regions of Russia and the Near Abroad. And most of them came to Yugra KhMAD for a "pretty penny", although now, of course, the difference in the level of wages is not so big. As a result, corporate executives have to set high salaries and even higher incentive payments to attract high-quality employees. However, from some point on, the increase in wages begins to be taken for granted, and does not lead to a comparable increase in the productivity and efficiency of workers.

3. The trap of low unemployment.

Due to the fact that the population of Yugra KhMAD is highly mobile, at the slightest deterioration in its socio-economic situation, or at the slightest opportunity to find a job with a comparable salary on the "mainland", highly qualified specialists "break down" and leave very quickly. As a result, there is almost always a shortage of personnel and very often the "cool" positions are forced to hire employees who either do not have sufficient qualifications or do not have sufficient experience. That is, there is an unnecessarily fast career advancement.

\section{Results and discussion}

\subsection{Modification of internal corporate institutions under the influence of digitalization}

Digitalization has a significant impact on internal corporate institutions, since itself significantly reduces transaction costs, of course, after the costs of its implementation have been overcome.

The impact of digitalization on internal corporate institutions is manifested in the following:

- large formalization and algorithmicization, that is, many norms and rules need to be detailed more carefully in order for them to work within information systems, and these norms and rules should be set forth in the form of consistent algorithms.

- increase in the amount of information, incl. information noise, that is, the amount of both useful and useless information increases.

- reduction of informal communication, because on the one hand, there is less time for informal communication due to the increase in the amount of information; on the other hand, formal interactions penetrate into those channels that were previously used for informal communication and replace it.

Digitalization makes it possible to overcome some of the institutional traps of intracorporate institutions. For example, the trap of information asymmetry can be overcome by increasing the amount of information and partial anonymity of participants in the discussion of a particular problem in social networks and instant messengers. As a result, the signs of a problem are more likely to appear than in the absence of information technology.

The trap of bureaucratization is weakened by the transfer of approval processes to electronic mode, thanks to which it is immediately clear at what of the approval stages the document is "stuck" and which of the employees is slowing down this process.

The trap of incentive payments can be smoothed out due to the algorithmization of the payroll process, when the decision on the amount of incentive payments is made based on 
the achievement or non-achievement of certain objective indicators, i.e. through the introduction of a "smart contract" [3, p. 42].

The low unemployment trap can also be partially overcome by actively engaging the remote workers.

At the same time, informatization leads to the emergence of new institutional traps of intracorporate institutions:

1. The ease of interaction trap

This trap is due to the fact that thanks to information technology, it has become very easy and simple to organize interaction with any employee, both in your own company and in other organizations. However, since the need for interaction can find a person in the most unforeseen situations (driving, in a restaurant, at night, etc.), he can answer "automatically" without thinking too much about the essence of the problem.

\section{Trap of confidence in the algorithms}

Here the problem is somewhat different and is connected with the fact that with the maximum formalization and algorithmization of intracorporate institutions, people begin to trust them too much. For example, the problem of copy-paste in documents, when the text wanders from one document to another without making any changes. But more serious situations arise where algorithms replace a person when performing monotonous work: sending letters, calculating salaries, etc. Since no algorithm can take into account all possible options, this leads to incidents and unpleasant situations. Also, employees who are well versed in the mechanism of the algorithm can artificially "wind up" their indicators and receive unjustified additional incentive payments.

\subsection{Impact of the coronavirus pandemic on the pace of digitalization of internal corporate institutions}

The coronavirus pandemic has unambiguously accelerated the processes of digitalization of internal corporate institutions, which had already been going on before, but not at such a pace.

The most obvious manifestation of the acceleration of digitalization of intracorporate institutions was the widespread transfer of employees to work remotely. Firms en masse began to provide the employees with the equipment and software necessary for full-fledged remote work: corporate mail programs (if had not existed before), equipment (laptops, webcams) and software for video conferencing and remote electronic document management, electronic digital signatures, etc. Naturally, it also required retraining of workers, especially the older ones.

Less noticeable is the acceleration of the processes of replacing the workers with robots and algorithms. Even before the pandemic, Sberbank began replacing the lawyers and call center employees with bots, and now other companies have picked up this trend. However, the mass introduction of robots in physical form has not yet taken place in Yugra, apparently shift workers, even taking into account the additional costs of providing the sanitary standards and sick leave, cost oil and gas companies cheaper than quadrocopters, drones and robotic dogs.

A new trend in digitalization, which manifested itself precisely during the pandemic, was the growing interest in contactless methods of interaction and transfer of objects. For example, many companies began to install non-contact temperature measurement systems, and there was also interest in installing the postamats.

\section{Conclusions}


Thus, it should be noted that the impact of digitalization on the evolution of internal corporate institutions in the northern resource-extraction region is ambiguous. On the one hand, some internal corporate institutions have become significantly more efficient thanks to digitalization, which helps to overcome a number of old institutional traps. On the other hand, digitalization leads to the emergence of new problems and new institutional traps.

At the same time, in the northern resource-extraction region, the evolution of intracorporate institutions proceeds within the framework of all-Russian trends, but has its own specifics, which is also influenced by digitalization.

The coronavirus pandemic has had an impact in the sense that the pace of digitalization in general has accelerated, but in Yugra KhMAD they still lag behind the global trends.

\section{Acknowledgments}

Participation in the conference and publication was funded by the Science Foundation of the Yugorsk State University, grant No. 17-02-07/57 dated February 14, 2020.

\section{References}

1. V. F. Islamutdinov, Journal of Institutional Studies, 12(3), 142 (2020)

2. Yu. I. Gribanov, Digital transformation of socio-economic systems based on the development of the institution of service integration, Doctoral thesis, 355 (2019)

3. M.V. Safronchuk, Digital Economy, 2(3), 38 (2018)

4. A.V. Parshin, Social policy and sociology, 1, 179 (2019)

5. T.V. Kramin, Intrafirm institutions as an element of company value management, https://www.researchgate.net/

6. H. Lipiäinen, K. Karjaluoto, M. Nevalainen, Corporate Communications: An International Journal, 19(3), 275 (2014)

7. M. Rachinger, R. Rauter, Ch. Müller, W. Vorraber, E. Schirgi, Journal of Manufacturing Technology Management (2018)

8. N. Urbach, M. Röglinger, Introduction to Digitalization Cases: How Organizations Rethink Their Business for the Digital Age, Chapter (2019)

9. B. Grab, M. Olaru, R.M. Gavril, The impact of digital transformation on strategic business management, https://www.researchgate.net/

10. U.S. Foerster-Metz, K. Marquardt, N. Golowko, A. Kompalla, Ch. Hell, Journal of EU Research in Business , 340873 (2018) 